\title{
Effect of YoYo Bitters on the Dissolution of Lisinopril Tablets
}

e-mail:olubunmicares@yahoo.com

\author{
A. Ayandokun Olubunmi ${ }^{1, *}$, O. Oyetunde Olubukola ${ }^{1}$, and O. Akinleye Moshood ${ }^{2}$ \\ ${ }^{1}$ Department of Clinical Pharmacy and Biopharmacy, Faculty of Pharmacy, University of Lagos, Nigeria \\ 2 Department of Pharmaceutical Chemistry, Faculty of Pharmacy, University of Lagos, Nigeria
}

\begin{abstract}
Lisinopril is an angiotensin converting enzyme inhibitor (ACEI), effective in lowering blood pressure in all grades of essential and renovascular hypertension. YoYo Cleanser Bitters is a liquid oral herbal medication reported to be beneficial in the management of illnesses such as diabetes, hypertension, and obesity, and for the general well-being of the body. The use of herbal bitters like YoYo Bitters is high in Nigeria, especially among patients with chronic illnesses like hypertension and diabetes. The aim of the study was to determine the effect of YoYo Bitters on the dissolution profile of lisinopril tablets.

In vitro dissolution of lisinopril tablets was studied in the presence and absence of YoYo Bitters at $\mathrm{pH} 1.2,4.5$, and 6.8 using USP Apparatus 2 at $50 \mathrm{rpm}$. Twelve tablets from the same batch were used according to USP specification, and sampling was done at 5, 10, 15, 30, 45, and 60 min. Analysis of lisinopril was done using high performance liquid chromatography (HPLC) coupled with a UV detector.

Results of the study show that at $\mathrm{pH} 1.2$, the dissolution of lisinopril tablets increased significantly in the presence of YoYo Bitters $(p=0.0015)$. At $\mathrm{pH} 4.5$, there was no statistically significant difference between the dissolution of lisinopril tablets with and without YoYo Bitters $(p=0.1232)$. At $\mathrm{pH} 6.8$, the dissolution of lisinopril tablets decreased significantly in the presence of YoYo Bitters $(p=0.0140)$.

Therefore, coadministration of YoYo Bitters and lisinopril tablets could lead to alteration in the dissolution of lisinopril and consequently change its bioavailability.
\end{abstract}

KEYWORDS: Dissolution; lisinopril tablet; YoYo Bitters.

\section{INTRODUCTION}

Y oYo Bitters is an herbal oral preparation popularly used in Southwest Nigeria. It is made from a blend of various parts of plants such as Aloe vera, Cinnamum aromaticum, Citrus aurantifolia, Acinos arvensis, and Chenopodium murale. It is said to be effective in the prevention of kidney and bladder infections. It is also claimed to help to normalize intestinal movement, regulate blood pressure, facilitate digestion, and prevent disorders like ulcers, gastritis, insomnia, stress, depression, and control of body weight (1).

Preliminary research carried out in some community pharmacies in Lagos, Nigeria, showed that the rate at which bitters are stocked is high, and YoYo Bitters is one of the fast-moving bitters. The high demand in pharmacies occurs especially among patients with chronic diseases owing to the beneficial effects reported by the manufacturer through intensive advertisement of the product and the claim that hypertensive patients would benefit from its daily use (2).

Lisinopril is a dicarboxyl-containing angiotensin- converting enzyme inhibitor (ACEI). It has therapeutic uses in hypertension, left ventricular systolic dysfunction, acute myocardial infarction, congestive heart disease, chronic renal failure, renoprotection in diabetic nephropathy, and in patients at high risk of cardiovascular events (3). ACEls like lisinopril improve endothelial function and reduce cardiovascular events more than other antihypertensive drug (3). Lisinopril has a good tolerability profile (4). Economic studies suggest that lisinopril is cost-saving compared with other ACEls in some markets (5). This may also be responsible for its increased use among hypertensive patients.

Herb-drug interaction refers to the possibility of an herbal drug altering the bioavailability or clinical effectiveness of a conventional drug when given concurrently. The net result may be an increase or decrease in the effect of the drugs (6). Coadministration of herbal medicines with orthodox drugs increases the possibilities of herb-drug interaction. Ginkgo biloba was reported (7) to cause bleeding with warfarin or acetylsalicylic acid. Hypericum perforatum (St. John's wort) has been reported (8) to decrease plasma concentrations of cyclosporine,

*Corresponding author. 
tacrolimus, oral contraceptives, simvastatin, nifedipine, and verapamil.

It was reported in a study carried out in Nigeria (1) that YoYo Bitters inhibited the metabolism of paracetamol tablets in some human subjects. The use of herbal medications is increasing in Nigeria (9). The use is common among patients that are on some medications used for the treatment of chronic diseases like hypertension and diabetes $(10,11)$.

Both the incidence of hypertension and the use of herbal bitters are increasing in the general population, setting the stage for potential coadministration of antihypertensives and herbal remedies. The Joint National Committee on the Prevention, Detection, Evaluation, and Treatment of high blood pressure (JNC 7) has advocated the use of ACEls as a first line in the management of hypertension (12). For this reason, a cost-effective ACEI like lisinopril is a likely choice, and the coadministration of lisinopril with YoYo Bitters is likely to occur.

Drugs must be available in the systemic circulation to be efficacious. The process of bioavailability involves two stages: dissolution and absorption/permeability. Any interruption in the process of dissolution could affect the amount of the active drug in the systemic circulation, thereby altering the clinical effect of the drug.

In vitro dissolution measures the rate and extent of drug dissolution or release. It determines the cumulative amount of drug that goes into solution as a function of time (13). It is a useful test to forecast the in vivo performance of a drug product, and it potentially reduces the number of bioavailability/bioequivalence studies required (14).

Since there is a paucity of data concerning the effect of herbal bitters on the dissolution of lisinopril tablets, it is therefore necessary to investigate the effect that YoYo Bitters may have on the dissolution profile of lisinopril tablets.

\section{MATERIALS AND METHODS \\ Materials}

Lisinopril dihydrate 100\% (USP) and diclofenac (USP) Reference Standards were obtained from the USP. Lisinopril tablets 10-mg (Zestril) and YoYo Bitters (Table 1) were bought from a registered pharmacy in Lagos, Nigeria. Concentrated hydrochloric acid (Sigma-Aldrich, Germany), glacial acetic acid (Sigma-Aldrich, Germany), potassium dihydrogen phosphate (JT Baker, USA), orthophosphoric acid $85 \%$ (Merck, Germany), sodium hydroxide pellets (JT Baker, USA), ammonium acetate (Lab Tech Chemicals), hexane-1-sulphonic acid sodium salt (ROMIL-SpR, GB), methanol HPLC grade 99\% (Lichrosolv), and acetonitrile HPLC grade 99\% (Lichrosolv) were obtained.

\section{Physicochemical Characterization of Lisinopril Tablets and YoYo Bitters}

Weight uniformity, hardness, friability, and assay of lisinopril tablets were carried out according to the British
Pharmacopoeia (BP) method (15).

The color of YoYo Bitters was determined by visual inspection of the liquid preparation and recorded. The taste and $\mathrm{pH}$ of the herbal product was also determined.

Table 1. History of Test Drugs

\begin{tabular}{|c|c|c|c|c|c|}
\hline Drug & Manufacturer & $\begin{array}{c}\text { Batch } \\
\text { Number }\end{array}$ & $\begin{array}{c}\text { Manufacturing } \\
\text { Date }\end{array}$ & $\begin{array}{c}\text { Expiry } \\
\text { Date }\end{array}$ & NAFDAC \\
\hline $\begin{array}{c}\text { Lisinopril } \\
10-\mathrm{mg} \\
\text { Tablet } \\
\text { (Zestril) }\end{array}$ & $\begin{array}{c}\text { Astra Zeneca } \\
\text { UK Limited }\end{array}$ & JE551 & $06-2011$ & $06-2015$ & $04-9760$ \\
\hline $\begin{array}{c}\text { YoYo } \\
\text { Bitters }\end{array}$ & $\begin{array}{c}\text { ABLLAT } \\
\text { Company } \\
\text { Nigeria } \\
\text { Limited }\end{array}$ & HBB200/12 & $03-2012$ & $03-2013$ & A7-1055L \\
\hline
\end{tabular}

\section{In Vitro Dissolution Test}

In vitro dissolution was carried out using tablet dissolution test USP Apparatus 2 (paddle). The dissolution tests were carried out in three media: $0.1 \mathrm{~N} \mathrm{HCl}$ at pH 1.2, $\mathrm{pH}$ 4.5 acetate buffer, and $\mathrm{pH} 6.8$ phosphate buffer. A volume of $900 \mathrm{~mL}$ of the different dissolution media was used, and the temperature was maintained at $37 \pm 0.5^{\circ} \mathrm{C}$ at a fixed speed of $50 \mathrm{rpm}$. Twelve units were tested according to FDA and USP specifications. A tablet was put in each vessel, and the equipment was operated for one hour. Sample aliquots of 5 $\mathrm{mL}$ were taken at $5,10,15,30,45$, and $60 \mathrm{~min}$ and replaced with $5 \mathrm{~mL}$ of fresh dissolution medium to maintain sink conditions. Each of the withdrawn samples was filtered with the aid of a $0.45-\mu \mathrm{m}$ syringe filter. The filtrate was then analyzed by HPLC-UV. The experiment was carried out in two parts, lisinopril tablets alone and lisinopril tablets with YoYo Bitters in the three different media.

\section{Preparation of Dissolution Media}

In preparing $1000 \mathrm{~mL}$ of the dissolution medium, 300 $\mathrm{mL}$ of YoYo Bitters was measured in a $1000 \mathrm{~mL}$ measuring cylinder, and $0.1 \mathrm{~N} \mathrm{HCl}$ was added to make $1 \mathrm{~L}$ of the dissolution medium. For the dissolution test, $900 \mathrm{~mL}$ of medium was used, and part of the remaining volume was used to maintain sink conditions. The same procedure was repeated for acetate buffer and phosphate buffer. The $0.1 \mathrm{~N} \mathrm{HCl}$ and acetate buffer were prepared according to the $B P$ method (15), while phosphate buffer was prepared according to USP (16).

\section{High Performance Liquid Chromatography}

The chromatographic procedure was carried out using a stainless steel Eclipse SB-C18, $4.6 \times 150 \mathrm{~mm}, 5-\mu \mathrm{m}$ column (Agilent) maintained at $40{ }^{\circ} \mathrm{C}$. The mobile phase was prepared by adding $200 \mathrm{~mL}$ of acetonitrile to $800 \mathrm{~mL}$ of a $0.408 \% \mathrm{w} / \mathrm{v}$ solution of anhydrous potassium dihydrogen orthophosphate adjusted to $\mathrm{pH} 2.0$ with orthophosphoric acid containing $0.125 \% \mathrm{w} / \mathrm{v}$ of sodium hexanesulphonate. The mobile phase was filtered with the aid of a $0.45-\mu \mathrm{m}$ Millipore filter. The flow rate of the mobile phase was $1 \mathrm{~mL} /$ 
min. The detector wavelength was $215 \mathrm{~nm}$. The mobile phase was passed through the column for at least $30 \mathrm{~min}$ before starting the chromatography.

\section{Data Analysis}

GraphPad Prism 6.0 software (La Jolla, CA) was used in the analysis of the data using paired $t$-test at level of significance of $p<0.05$.

\section{RESULTS}

Lisinopril tablet is a round, light pink tablet embossed with the shape of a heart and ZESTRIL 10. Table 2 shows the physicochemical parameters of lisinopril tablets. Table 3 represents the physical properties of YoYo Bitters. Table 4 lists the percentages of lisinopril released at $\mathrm{pH} 1.2,4.5$, and 6.8. Figures 1-3 show the dissolution profiles of lisinopril tablets alone and in the presence of YoYo Bitters in the three media.

Table 2. Physicochemical Parameters of Lisinopril Tablets

\begin{tabular}{|l|l|}
\hline \multicolumn{1}{|c|}{ Parameter } & \multicolumn{1}{c|}{ Observation } \\
\hline Uniformity of weight (\% deviation) & $1.3 \pm 1.24$ \\
Hardness (kg-cm) & $3.5 \pm 0.40$ \\
Friability (\%) & 0.2 \\
Purity (\%) & $96.2 \pm 4.46$ \\
\hline
\end{tabular}

Table 3. Physical Properties of YoYo Bitters

\begin{tabular}{|l|l|}
\hline \multicolumn{1}{|c|}{ Parameter } & \multicolumn{1}{|c|}{ Observation } \\
\hline Color & Brownish black \\
Taste & Bitter \\
$\mathrm{pH}$ & 2.9 \\
\hline
\end{tabular}

\section{DISCUSSION}

Dissolution of a drug in solid dosage form into an aqueous medium is critical to its absorption, which has an impact on its bioavailability and hence therapeutic efficacy. Variables such as uniformity of weight, hardness, friability, and percentage purity also play important roles in efficient release of the active ingredient of the drug for systemic absorption (17). These parameters were therefore evaluated before carrying out the dissolution studies. The results conformed to the specifications in the $B P(15)$. The $\mathrm{pH}$ of YoYo Bitters is 2.9, thus it is acidic in nature. This could be because of some of its constituents such as Cinnamon aromaticum, Citrus aurantifolia, and Acinos arvensis. Cinnamon aromaticum contains cinnamic acid, Citrus aurantifolia contains citric acid and ascorbic acid, while Acinos arvensis contains Linolenic acid (19).

In this study, at $\mathrm{pH} \mathrm{1.2,} \mathrm{which} \mathrm{mimics} \mathrm{acidic} \mathrm{condition}$ of the stomach, the percentage release of lisinopril alone without YoYo Bitters did not conform to the dissolution monograph of lisinopril as specified in BP 2007, which states that the amount of lisinopril released should not be less

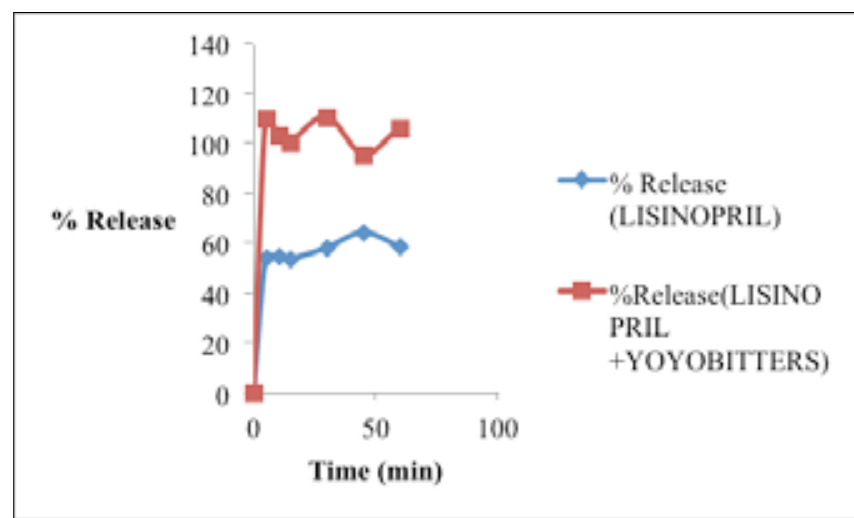

Figure 1. Dissolution profile of lisinopril tablets alone and in the presence of YoYo Bitters at $\mathrm{pH}$ 1.2.

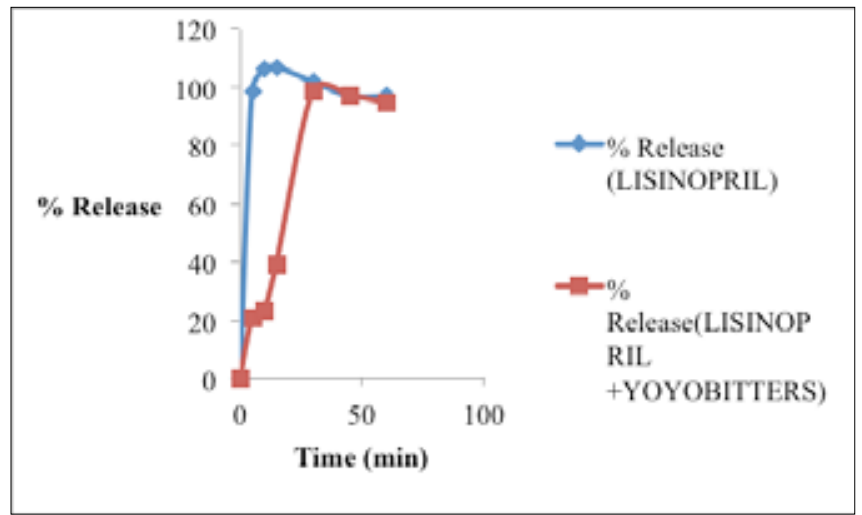

Figure 2. Dissolution profile of lisinopril tablets alone and in the presence of YoYo Bitters at $\mathrm{pH}$ 4.5.

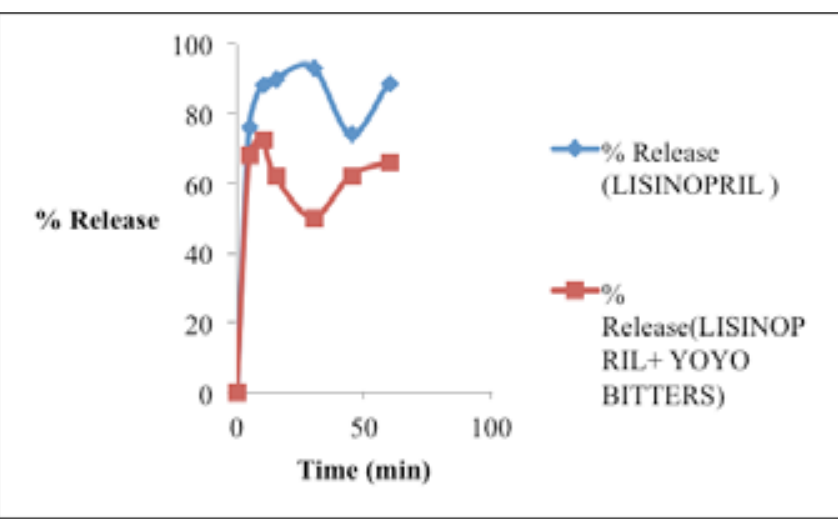

Figure 3. Dissolution profile of lisinopril tablets alone and in the presence of YoYo Bitters at $\mathrm{pH} 6.8$.

than $85 \%$ of the stated amount at $30 \mathrm{~min}$. This means that it failed the dissolution test at this $\mathrm{pH}$. In the presence of YoYo Bitters, the percentage release of lisinopril increased. The paired $t$-test of percentage release of lisinopril tablets alone and lisinopril tablets with YoYo Bitters showed a significant difference $(p=0.0015)$. YoYo Bitters could have enhanced the solubility of lisinopril tablet, thereby aiding the release of lisinopril. An increase in the solubility of a drug increases absorption, which might increase the bioavailability of the drug. An increase in the bioavailability of lisinopril could lead to an increase in the therapeutic concentration, which could have serious clinical implications like hypotension 
Table 4. Percentage of Lisinopril Released at $\mathrm{pH} 1.2,4.5$, and 6.8

\begin{tabular}{|c|c|c|c|c|c|c|}
\hline \multirow{2}{*}{$\begin{array}{c}\text { Sampling time } \\
\text { (min) }\end{array}$} & \multicolumn{2}{|c|}{ \% Release at pH1.2 } & \multicolumn{2}{c|}{ \% Release at pH 4.5 } & \multicolumn{2}{c|}{ \% Release at pH 6.8 } \\
\cline { 2 - 7 } & Lisinopril Alone & $\begin{array}{c}\text { Lisinopril + } \\
\text { YoYo Bitters }\end{array}$ & Lisinopril Alone & $\begin{array}{c}\text { Lisinopril + } \\
\text { YoYo Bitters }\end{array}$ & Lisinopril Alone & $\begin{array}{c}\text { Lisinopril + } \\
\text { YoYo Bitters }\end{array}$ \\
\hline 5 & $54.0 \pm 2.72$ & $110.05 \pm 20.53$ & $98.94 \pm 3.45$ & $20.8 \pm 5.48$ & $76.12 \pm 4.32$ & $68.05 \pm 7.79$ \\
\hline 10 & $54.5 \pm 2.69$ & $103.02 \pm 13.50$ & $106.39 \pm 3.88$ & $23.51 \pm 6.00$ & $88.12 \pm 6.16$ & $72.63 \pm 4.73$ \\
\hline 15 & $53.79 \pm 4.04$ & $100.44 \pm 15.49$ & $107.07 \pm 2.45$ & $39.56 \pm 5.17$ & $89.63 \pm 5.77$ & $62.22 \pm 7.70$ \\
\hline 30 & $58.15 \pm 4.23$ & $110.58 \pm 11.93$ & $101.97 \pm 5.12$ & $98.79 \pm 5.27$ & $93.22 \pm 2.32$ & $49.99 \pm 1.90$ \\
\hline 45 & $64.38 \pm 5.26$ & $95.33 \pm 19.30$ & $97.14 \pm 3.59$ & $97.3 \pm 4.34$ & $73.97 \pm 5.77$ & $62.01 \pm 9.98$ \\
\hline 60 & $58.58 \pm 2.36$ & $106.8 \pm 10.88$ & $97.14 \pm 3.59$ & $94.72 \pm 2.12$ & $88.52 \pm 15.53$ & $65.89 \pm 6.94$ \\
\hline
\end{tabular}

and shock if above the maximum safe concentration.

The percentage release of lisinopril alone at $\mathrm{pH} 4.5$ conformed to the specification in the monograph. In the presence of YoYo Bitters, the change in the percentage release of lisinopril was not statistically significant $(p=0.1232)$. This $\mathrm{pH}$ mimics the transit between the stomach and small intestine.

At $\mathrm{pH} 6.8$, the percentage release of lisinopril alone also conformed to the specification in the monograph. In the presence of YoYo Bitters, the percentage release of lisinopril was lower than the result obtained from lisinopril alone. The statistical test of the difference showed it to be statistically significant $(p=0.0140)$. HPLC analysis of YoYo Bitters eluted a number of substances that could not be identified. This is not surprising as it is a mixture of about five herbs. These constituents could have interacted with the process of dissolution at this stage.

A $\mathrm{pH}$ of 6.8 mimics intestinal conditions where absorption takes place; therefore, any dissolution observed here is critical to the absorption or bioavailability of the drug. Decrease in dissolution of lisinopril tablets could lead to decrease in absorption of the active ingredient and in turn bioavailability of the drug. Decreased bioavailability could lead to therapeutic failure, which could lead to uncontrolled hypertension posing a threat to some organs of the body like the heart, eyes, brain, and kidneys, thereby compromising positive clinical outcomes in patients taking such medications. A report (20) states that herbs like Aloe vera and other anthraquinone-containing herbs could inhibit absorption of conventional drugs as a result of chelation or formation of insoluble complexes with the drugs.

Concurrent use of YoYo Bitters and lisinopril tablets could increase the potential for herb-drug interaction, which may have significant clinical consequences. Health care professionals therefore have the responsibility of educating patients about this behavior. Coadministration of an herbal product like YoYo Bitters could affect the dissolution of lisinopril tablets in various ways, either by increasing or decreasing the percentage release of the drug depending on the $\mathrm{pH}$ of the absorption site. Coadministration of these two medications should therefore be done with great caution to prevent serious clinical consequences.

\section{CONCLUSION}

YoYo Bitters significantly increased the dissolution of lisinopril tablets at $\mathrm{pH}$ 1.2. There was no statistically significant difference between the dissolution of lisinopril tablets with and without YoYo Bitters at $\mathrm{pH}$ 4.5. The dissolution of lisinopril tablets decreased significantly in the presence of YoYo Bitters at $\mathrm{pH} 6.8$.

\section{REFERENCES}

1. Kumdi, B. V.; Kolawole, J. A.; Apeh, E. The effect of Yoyo bitters on the pharmacokinetics of single oral dose paracetamol tablet in human volunteers. Int. J. Biol. Chem. Sci. 2011, 5 (2), 717-723.

2. YoYo Cleanser Bitters. Abllat Nigeria Limited Web site. http://abllat.com/yoyobitters.html (accessed Jan 22, 2015).

3. Brunton, L.; Parker, K.; Blumenthal, D.; Buxton, L., Eds. Goodman \& Gilman's Manual of Pharmacology and Therapeutics, International Edition; Mc Graw-Hill: New York, 2008; pp 522-525.

4. Goa, K. L.; Balfour, J. A.; Zuanetti, G. Lisinopril: A review of its pharmacology and clinical efficacy in the early management of acute myocardial infarction. Drugs 1996, 52 (4), 564-588.

5. Langtry, H. D.; Markham, A. Lisinopril. A review of its pharmacology and clinical efficacy in elderly patients. Drugs Aging 1997, 10 (2), 131-166. DOI: 10.2165/00002512-199710020-00006.

6. Chen, J. Recognition and Prevention of Herb-Drug Interaction, 1998. Acupuncture.com Web site. www. acupuncture.com/herbs/drugherb.htm (accessed Jan 9, 2015).

7. Hu, Z.; Yang, X.; Ho, P. C. L.; Chan, S. Y.; Heng, P. W. S.; Chan, E.; Duan, W.; Koh, H. L.; Zhou, S. HerbDrug Interactions. Drugs 2005, 65 (9), 1239-1282. DOI: 10.2165/00003495-200565090-00005.

8. Borrelli, F.; Izzo, A. A. Herb-Drug Interactions with St John's Wort (Hypericum perforatum): an Update on Clinical Observation. AAPS J. 2009, 11 (4), 710-727. DOI: 10.1208/s12248-009-9146-8.

9. Oreagba, I. A.; Oshikoya, K. A.; Amachree, M. Herbal medicine use among urban residents in Lagos, Nigeria. BMC Complementary Altern. Med. [Online] 2011, 11, Article 117. http://www.biomedcentral.com/content/ 
pdf/1472-6882-11-117.pdf (accessed Jan 9, 2015). DOI: $10.1186 / 1472-6882-11-117$.

10. Amira, O. C.; Okubadejo, N. U. Frequency of complementary and alternative medicine utilization in hypertensive patients attending an urban tertiary care centre in Nigeria. BMC Complementary Altern. Med. [Online] 2007, 7 Article 30. http://www.biomedcentral. com/content/pdf/1472-6882-7-30.pdf (accessed Jan 9, 2015). DOI: 10.1186/1472-6882-7-30.

11. Ogbera, A. O.; Dada, O.; Adeyeye, F.; Jewo, P. I. Complementary and alternative medicine use in diabetes mellitus. West Afr. J. Med. 2010, 29 (3), 158162.

12. Martin, J. Hypertension Guidelines: Revisiting the JNC 7 Recommendations. J. Lancaster Gen. Hosp. 2008, 3 (3), 91-97.

13. Gray, V.; Lozano, R.; Tong, C.; Nickerson, B.; Wang, Q.; Mao, Y.; Löbenberg, R.; Mirza, T. The Value of In Vitro Dissolution in Drug Development. Pharm. Technol. 2009, 33 (4), 52-64.

14. In Vitro Dissolution Testing For Solid Oral Dosage Forms; Technical Brief 2010 Vol. 5. Particle Sciences
Drug Development Services [Online]. http:// www.particlesciences.com/docs/technical_briefs/ TB_2010_5.pdf (accessed Jan 9, 2015).

15. British Pharmacopoeia; The Stationery Office: London, 2007.

16. The United States Pharmacopeia and National Formulary USP 27-NF 22; The United States Pharmacopeial Convention, Inc.: Rockville, MD, 2004.

17. Akinleye, M. O.; Jolaoso, A. A.; Coker, H. A. B. Comparative Dissolution Profiles of Representative Quinolones in Different Media. Niger. Q. J. Hosp. Med. 2011, 21 (1), 1-8.

18. Odeku, O. Friability. In Tablet Evaluation Tests [Online]; Pharminfo.net: Hyderabad, India, 2008. http://www. pharmainfo.net/tablet-evaluation-tests/mechanicalstrength-tablets/friability (accessed Jan 9, 2015).

19. Stojanović, G.; Golubović, T.; Kitić, D.; Palić, R. Acinos species: Chemical composition, antimicrobial and antioxidative activity. J. Med. Plants Res. 2009, 3 (13), 1240-1247.

20. Chavez, M. L.; MacKinnon, K. J.; Swanson, L. S. HerbalDrug Interactions. InetCE 2005, 9 (10), 1-30. 